\title{
Predictors of neurological recovery after surgery of metastatic epidural spinal cord compression
}

\author{
Matthias Setzer*\#, Christian T. Ulrich\#, Stephan Dützmann, Volker Seifert, Lutz M. Weise ${ }^{\S}$ and Gerhard Marquardt ${ }^{\S}$
}

Neurosurgical Hospital, University Hospital Frankfurt, Goethe-University, Frankfurt/Main, Germany

"Matthias Setzer and Christian T. Ulrich contributed equally to this manuscript

${ }^{\varsigma}$ Lutz M. Weise and Gerhard Marquardt contributed equally to this manuscript

\begin{abstract}
Objective: The aim of this study was to identify potential preoperative predictors (inclusive time between onset of motor weakness and surgical decompression) of neurological function and ambulation in a consecutive series of patients with MESCC treated with urgent spinal cord decompression.

Material/Methods: 327 patients with MESCC who underwent emergency laminectomy were reviewed retrospectively. Variables evaluated were: age, gender, site of primary tumor, location of spinal cord compression, location and number of affected segments, time between onset of neurological deficits to surgical decompression, the pre- and early postoperative ASIA scores, pre- and postoperative ability to walk and to ambulate and the pre- and postoperative quality of walking. Variables were analyzed with uni- and multivariate methods. A backward stepwise binary logistic regression analysis was performed to determine the effect of the evaluated variables in a multivariate model.

Results: The majority of the patients were assigned to ASIA impairment scale grade D. At admission $49.5 \%$ of the patients could walk and $50.5 \%$ of the patients were not able to walk. The mean time between onset of neurological deficits and decompression was 114.72 hours $+/-173.41$ (range $2-1800$ hours). Univariate analyses identified preoperative ASIA impairment scale grades, the ability to walk preoperatively, tumor localization, age and duration of symptom (time interval between onset of motor weakness and surgical decompression) as predictors for neurological improvement and outcome.
\end{abstract}

In a multivariate model time between onset of motor weakness and surgical decompression $(\mathrm{p}<0,05)$ and the ability to walk preoperatively $(\mathrm{p}<0.0001)$ were significant independent predictors for improvement of the ability to walk.

Conclusion: Early surgical decompression is important for neurological recovery in patients with MESCC especially with rapid neurological deterioration.

\section{Introduction}

Metastatic epidural spinal cord compression (MESCC) is a relatively common complication in up to $5-14 \%$ of patients with cancer. It is expected that symptomatic metastatic spinal disease will become more prevalent as survival rates for many common cancers improve [1,2]. Pain is the most common presenting symptom, occurring in approximately $83-95 \%$ of patients. The second most common symptom is motor dysfunction. Approximately $60-85 \%$ of patients with MESCC show motor weakness at the time of diagnosis [3-6]. However, the accurate diagnosis is often delayed due to insidious progression of the symptoms and can end in a disastrous neurological outcome with significant motor deficits and loss of ambulation [7]. Although some of these patients can be treated non surgically $[8,9]$ the acute onset of a neurological deficit due to MESCC is traditionally considered as an emergency that require an immediate treatment [10]. Despite this widely accepted dogma only few studies examined the impact of time to decompressive surgery on the neurological outcome of patients with MESCC so far $[9,11,12]$.

In addition several studies reported that the preoperative ambulatory status is a significant predictor of postoperative motor function and ambulation [13-20].

The aim of this study was to identify potential preoperative predictors (inclusive time between onset of motor weakness and surgical decompression) of neurological function and ambulation in a consecutive series of patients with MESCC treated with urgent spinal cord decompression.

\section{Material and methods}

\section{Patient selection}

This study included 327 consecutive patients with spinal metastases and MESCC who underwent surgery at the Neurosurgical Hospital of the Goethe-University Frankfurt/Main. The compressive effect of the metastasis could include more than one level but had to be restricted to one area and to be the cause of the motor weakness. Only lumbar tumors with compression of the conus were considered. Tumors involving lumbar segments with exclusive compression of the cauda equina or spinal nerve roots were not included. The patient's records were retrospectively reviewed. The study was approved by the Institutional Review Board of the Goethe University Frankfurt and was conducted according to the Helsinki Declaration.

\section{Management protocol and surgical procedure}

All patients underwent preoperative MR imaging investigation

Correspondence to: Privatdozent Dr. Matthias Setzer, Neurosurgical Department, Neurocenter, University Hospital Frankfurt, Goethe University, Schleusenweg 2-16, 60528 Frankfurt am Main, Germany. Tel: +49 69 63015295, E-mail: Matthias.Setzer@kgu.de

Key words: Spinal Metastasis - MESCC - Dorsal Decompression - ASIA Score Ambulatory Status

Received: June 04, 2017; Accepted: June 26, 2017; Published: June 29, 2017 
confirming the MESCC at one area. The indication for operation was neurological impairment with motor deficits. Surgical interventions were performed as soon as possible after admission. The primary approach was posterior with or without instrumentation. On admission to hospital, the administration of dexamethasone was started with an intravenous bolus $(40 \mathrm{mg})$ and continued orally for 3 to 5 days postoperatively ( $4 \mathrm{mg}$ t.i.d.).

\section{Neurological and neuroradiological variables}

For each patient demographics, time of neurological event, admission, and operation, pre- and early postoperative neurological status (on admission and discharge) including ASIA impairment score [21] and ability to walk, and complications were recorded. Clinical variables considered for analysis were as follows: age (in years), primary tumor type, duration of symptoms (time between onset of motor weakness to decompression of spinal cord in hours), pre-, postoperative ASIA scale grades (on admission and discharge), pre, postoperative ability to walk, postoperative improvement of ability to walk (yes/no) and the quality of walking. Since the ability to walk and ambulation is most important for the determination of the quality of live even if the patient needs a walking aid (cane, walker) [22] the variables "improvement of ability to walk" and "improvement of ASIA impairment scale grades" were the main outcome variables evaluated. Other outcome variables were the postoperative ASIA scale grades, the postoperative ability to walk and the quality of walking, since it has been shown that the use of the variable "ability to walk" reduced observer biases associated with retrospective patient classifications $[5,14]$.

The neuroimaging confirmed an epidural tumor compression on one or more levels restricted to one area matching to the neurological deficits. The tumor location was evaluated with respect to the spinal cord (ventral, ventrolateral, dorsal, circumferential).

\section{Statistical analysis}

Statistical procedures were performed using a commercially available software package (IBM SPSS, version 18.0, IBM, Corp. Armonk, New York, USA). Categorical variables were analyzed using the chi-square test, continuous data with the Mann-Whitney U-test, and comparisons of multiple groups with the H-test of Kruskal-Wallis. Univariate analysis was performed to determine the effect of clinical and neuroimaging variables on short-term outcome after posterior decompression in MESCC. In a second step, a multivariate analysis was performed to find independent predictors for postoperative improvement of the ability to walk after surgical treatment by using a backward stepwise binary logistic regression analysis. Variables with significant probability values on univariate analyses were considered as potentially independent on multivariate analysis.

\section{Results}

\section{Basic characteristics}

In total 327 patients (191 men, 136 women) were included in the study. The age ranged from 21 to 93 years. The mean age was $60.9+/-$ 12.4 years. Further details of the patients' characteristics are given in Table 1 . The primary tumor types are listed in Table 2.

\section{Neurological status at admission}

All patients had motor deficits at admission. The majority of the patients were assigned to ASIA impairment scale grade D. At admission $49.5 \%$ of the patients could walk and $50.5 \%$ of the patients were not
Table 1. Patient characteristics and neuroradiological variables.

\begin{tabular}{|l|c|c|c|}
\hline \multicolumn{1}{|c|}{} & n & \% of total \\
\hline Gender (m/f) & Male/Female & $191 / 136$ & $58.4 / 41.6$ \\
\hline & Mean (SD) & $60.9+/-12.4$ & \\
\hline Affected Spinal Area & $20-40$ & 21 & 6.4 \\
\hline & $41-60$ & 123 & 37.6 \\
\hline & Craniocervical & 170 & 52.0 \\
\hline & Cervical & 21 & 4.0 \\
\hline & Cervicothoracic & 5 & 1.2 \\
\hline & Thoracic & 266 & 6.4 \\
\hline Tumor Localization & Thoracolumbar & 10 & 1.5 \\
\hline (with respect to spinal cord) & Lumbar & 21 & 31.3 \\
\hline & ventral & 142 & 6.4 \\
\hline & dorsal & 53 & 43.4 \\
\hline & ventrolateral & 84 & 16.2 \\
\hline Number of Affected & circumferential & 48 & 25.7 \\
\hline Segments & 1 & 117 & 14.7 \\
\hline & & & 35.8 \\
\hline & 2 & 129 & 39.4 \\
\hline & 3 & 2 & 19.0 \\
\hline & & & 5.8 \\
\hline & Median & & \\
\hline
\end{tabular}

Table 2. Primary tumor types.

\begin{tabular}{|l|c|c|}
\hline Primary Tumor Type & n & \% of total \\
\hline CUP & 23 & 7.0 \\
\hline Lymphoma & 28 & 8.6 \\
\hline Sarcoma & 22 & 6.7 \\
\hline Prostate & 38 & 11.6 \\
\hline NSCLC & 36 & 11.0 \\
\hline Plasmocytoma & 25 & 7.6 \\
\hline Melanoma & 12 & 3.7 \\
\hline Breast & 49 & 15.0 \\
\hline Renal Cell & 28 & 8.6 \\
\hline Nasopharyngeal & 5 & 1.5 \\
\hline SCLC & 12 & 3.7 \\
\hline Cervix Uteri & 2 & 0.6 \\
\hline Colorectal & 16 & 4.9 \\
\hline Liver & 2 & 0.6 \\
\hline Pancreatic & 2 & 1.2 \\
\hline Skin (Merkel Cell) & 3 & 0.6 \\
\hline Skin Squamous Cell & 1 & 0.9 \\
\hline Histiozytoma & 5 & 0.3 \\
\hline Esophageal & 1 & 1.5 \\
\hline Adrenal Gland & 6 & 0.3 \\
\hline Thyroid & 2 & 1.8 \\
\hline Ovarian & 3 & 0.6 \\
\hline Germ Cell & 27 & 0.9 \\
\hline Bladder & 2 & 0.6 \\
\hline Total & 2 & 100.0 \\
\hline Abre & & \\
\hline
\end{tabular}

Abbreviations: CUP $=$ Carcinoma with unknown primary, NSCLC $=$ non-small cell lung carcinoma, SCLC $=$ Small cell lung carcinoma

able to walk. The mean time between onset of neurological deficits and decompression was 114.72 hours +/- 173.41 (range 2 - 1800 hours) (Table 3).

\section{Neurological outcome}

After surgery (at discharge) 137 (41.9\%) patients improved on 
the ASIA impairment scale, 190 (58.1\%) did not. 250 (76.5\%) patients could walk. 98 (30\%) of them regained their ability to walk after surgery (Table 4).

\section{Univariate analyses}

\section{Association Between Clinical/Radiological and Outcome Variables}

Postoperative ASIA impairment scale grades: Significant differences between postoperative ASIA scale grades were found

Table 3. Preoperative neurological status variables.

\begin{tabular}{|c|c|c|c|}
\hline & & $\mathbf{n}$ & $\%$ of Total \\
\hline \multirow[t]{4}{*}{$\begin{array}{l}\text { ASIA Impairment Scale } \\
\text { Score }\end{array}$} & A & 18 & 5.5 \\
\hline & B & 20 & 6.1 \\
\hline & $\mathrm{C}$ & 74 & 22.6 \\
\hline & D & 215 & 65.7 \\
\hline \multirow[t]{2}{*}{ Abilitiy to Walk } & Yes & 162 & 49.5 \\
\hline & No & 165 & 50.5 \\
\hline \multirow[t]{3}{*}{ Quality of Walking } & Independent & 76 & 23.2 \\
\hline & With help & 87 & 26.6 \\
\hline & Unable to walk & 164 & 50.2 \\
\hline
\end{tabular}

Table 4. Postoperative neurological status variables.

\begin{tabular}{|l|c|c|c|}
\hline \multicolumn{1}{|c|}{} & $\mathbf{n}$ & \% of Total \\
\hline ASIA Impairrment Scale Grade & A & 0 & 0 \\
\hline & B & 14 & 4.3 \\
\hline & C & 40 & 12.2 \\
\hline Abilitiy to Walk & D & 218 & 66.7 \\
\hline & E & 55 & 16.8 \\
\hline Quality of Walking & Yes & 250 & 76.5 \\
\hline & No & 77 & 23.5 \\
\hline & Independent & 110 & 33.6 \\
\hline Improvement of & With help & 142 & 43.4 \\
\hline ASIA Impairment Scale Grade & Unable to walk & 75 & 22.9 \\
\hline & Yes & 137 & 41.9 \\
\hline Improvement of Walking & No & 190 & 58.1 \\
\hline & Yes & 98 & 30.0 \\
\hline
\end{tabular}

in the distribution of the preoperative ASIA impairment scale grades $(p<0.001)$. Specifically, less severely affected patients reached significantly better postoperative ASIA impairment scale grades than more severely affected patients. The variables mean duration of symptoms $(p<0.013)$ showed significant differences between the postoperative ASIA impairment scale grades. Good postoperative impairment scale grades had in average earlier surgery than bad ones (Table 5).

Postoperative ability to walk: Significant differences between postoperative ability to walk were found between the preoperative ASIA grades $(p<0.0001)$ and the preoperative ability to walk $(p<0.0001)$. The better the ASIA grades were preoperatively the higher was the probability to retain or regain the ability to walk after surgery. Patients with the ability to walk postoperatively were significantly younger (mean $60.2+/-12.8$ vs. $63.5+/-10.9 \mathrm{p}<0.032$ ) (Table 5).

Postoperative quality of walking: The postoperative quality of walking showed significant differences in the distribution of the preoperative ASIA grades $(p<0.0001)$. The better the preoperative ASIA grade was, the higher was the quality of walking postoperatively. Patients who could walk preoperatively had a significant higher postoperative quality of walking $(\mathrm{p}<0.0001)$. Younger patients had a significant higher postoperative quality of walking than older ones $(p<0.005)$. Significant differences were also found in the mean duration of symptoms and the postoperative quality of walking (Table 5).

No significant differences could be found for the outcome variables and the different tumor types.

Postoperative improvement of ASIA impairment scale grades and Postoperative improvement of walking: Significant differences for the "dynamic variables" postoperative improvement of ASIA impairment scale grades and postoperative improvement of walking were seen in the distribution of the preoperative ASIA grades $(\mathrm{p}<0.0001$ both) and the preoperative ability to walk ( $\mathrm{p}<0.0001$ both). The variable improvement of ASIA impairment Scale grades showed a trend for significance between the groups of tumor localization $(p<0.058)$ the variable improvement of walking showed significant differences in between the tumor localization groups $(p<0.027)$. More patients with ventrolateral and dorsal tumors showed an improvement of walking. Significant differences were found between the mean duration of

Table 5. Postoperative neurological status variables versus metrical clinical and radiological variables.

\begin{tabular}{|c|c|c|c|c|c|c|}
\hline & & \multicolumn{2}{|l|}{$\begin{array}{l}\text { Age in years } \\
(\text { mean +- SD) }\end{array}$} & \multicolumn{2}{|c|}{$\begin{array}{l}\text { Duration of symptoms } \\
\text { In hours } \\
\text { (mean +- SD) an) }\end{array}$} & $\begin{array}{l}\text { Number of segments } \\
\text { (median) }\end{array}$ \\
\hline $\begin{array}{l}\text { ASIA Impairrment Scale Grade } \\
\text { postoperative }\end{array}$ & $\begin{array}{l}\text { A } \\
\text { B } \\
\text { C } \\
\text { D } \\
\text { E }\end{array}$ & $\begin{array}{c}- \\
63.6+/-11.1 \\
61.7+/-11.0 \\
61.6+/-12.5 \\
57.4+/-13.0\end{array}$ & ns & \begin{tabular}{l}
\multicolumn{1}{c}{-} \\
$136.2+/-238.8$ \\
$117.2+/-168.8$ \\
$95.2+/-102.7$ \\
$46.3+/-32.8$
\end{tabular} & $\mathrm{p}<0.013$ & ns \\
\hline $\begin{array}{l}\text { Abilitiy to Walk } \\
\text { postoperative }\end{array}$ & $\begin{array}{l}\text { Yes } \\
\text { No }\end{array}$ & $\begin{array}{l}60.2+/-12.8 \\
63.5+/-10.9\end{array}$ & $\mathrm{p}<0,032$ & $\begin{array}{l}114.1+/-185.7 \\
114.8+/-126.5\end{array}$ & $\mathrm{~ns}$ & $\begin{array}{l}2 \\
2\end{array}$ \\
\hline $\begin{array}{l}\text { Quality of Walking } \\
\text { postoperative }\end{array}$ & $\begin{array}{l}\text { Independent } \\
\text { With help } \\
\text { Unable to walk }\end{array}$ & $\begin{array}{l}58.2+/-12.7 \\
61.5+/-12.8 \\
63.9+/-10.4\end{array}$ & $\mathrm{p}<0.005$ & $\begin{array}{l}119.0+/-145.6 \\
107.4+/-173.3 \\
121.1+/-191.1\end{array}$ & $\mathrm{p}<0.015$ & $\begin{array}{l}2 \\
2 \\
2\end{array}$ \\
\hline $\begin{array}{l}\text { Improvement of } \\
\text { ASIA Impairment Scale Grade }\end{array}$ & $\begin{array}{l}\text { Yes } \\
\text { No }\end{array}$ & $\begin{array}{l}60.8+/-13.1 \\
61.1+/-12.0\end{array}$ & $\mathrm{~ns}$ & $\begin{array}{l}113.6+/-196.7 \\
115.4+/-154.9\end{array}$ & $\mathrm{~ns}$ & $\begin{array}{l}2 \\
2\end{array}$ \\
\hline Improvement of Walking & $\begin{array}{l}\text { Yes } \\
\text { No }\end{array}$ & $\begin{array}{l}62.5+/-12.4 \\
60.3+/-12.4\end{array}$ & ns & $\begin{array}{r}79.0+/-132.2 \\
130.0+/-186.4\end{array}$ & $\mathrm{p}<0.001$ & $\begin{array}{l}2 \\
2\end{array}$ \\
\hline
\end{tabular}


symptoms of the patients with improvement and non-improvement $(79.0+/-132.2 \mathrm{~h}$ vs $130.0+/-186.4)$ (Table 5).

\section{Multivariate analyses}

With a backward stepwise method in a binary logistic regression, the multivariate relationships were analysed for the dependent (dichotomous) "postoperative improvement/no improvement of the ability to walk. Of the presumed predictor variables for improvement -preoperative ASIA grade, preoperative ability to walk and tumor localization duration of symptoms - preoperative ability to walk (OR $108.7,95 \%$ CI $25.8-457.9$ ) and duration of symptoms (OR $0.9895 \%$ CI 0.95-0.99) remained significant in the multivariate model.

\section{Discussion}

Malignant epidural spinal cord compression (MESCC) is a devastating complication in cancer patients with spinal metastases potentially leading to disability and massive reduction of life extpectancy. Apart from slowly growing metastases in a few tumor entities surgery of spinal metastases is generally considered as palliative as it does not cure the disease [12]. Survival rates after surgery of patients with MESCC range from 11-21 months [12].

However low growing tumor, absence of visceral metastasis, and lower degree of preoperative physical disability, as reflected by a higher score on the SF-36 physical component questionnaire have been identified to be predictors for an extended survival [23-25]. The percentage of cancer patients developing MESCC is estimated to $5-14 \%$ [23]. Advances in diagnosis and medical and surgical therapy has increased the su rvival rates in of patients with spinal metastases, thus it is reasonable to expect higher rates of patients with MESCC in the future $[1,2]$.

MESCC is a potential cause of neurological compromise and impairment of quality of life $[9,26]$. Depending from location, stability and symptoms of the spinal metastasis causing cord compression patients can be treated non-surgically however in most of the patients surgical decompression is required to preserve neurological function [9]. Recently clinically validated scores have been developed to help oncologists to assess spinal instability and to alleviate decision making regarding the best therapy [27-31].

\section{Neurological outcome after surgery}

Several studies have reported recovery rates ranging from $40 \%$ to $60 \%$ after decompressive surgery $[6,14,32]$. This is consistent with the results in this study with an ASIA impairment scale grade improvement of $41.9 \%$ and an improvement of walking of $30 \%$. Furthermore, severely impaired patients. This is also consistent with other studies $[12,14]$.

It has been a dogma for the last few decades in spine surgery that MESCC with consecutive neurological deficits requires an urgent, if not emergent, management. However surprisingly only very few studies have been published investigating the impact of duration of symptoms on neurological recovery [9]. 3 studies showed a significantly better neurological outcome for surgical decompression within $48 \mathrm{~h}$ after onset of symptoms $[9,12,14,33]$. Harris et al., [11] reported that a greater proportion undergoing emergency surgery, rather than electively (within $24 \mathrm{~h}$ ) on the next list showed functional improvement, with recovered mobility (61.5\% vs. $25 \%)$. However, the authors did not provide any time intervals between development of symptoms and surgical therapy. However delays in the exact diagnosis, referrals and treatment of patients with MESCC are well known [7,34]. Thus, it can be concluded that even the emergency surgery group in this study encompasses a significant portion of patients with a long duration of motor weakness. Regardless of these initial delays in referral, and even if the patient is incontinent and immobile the authors concluded that emergency spinal decompression is justified [11].

In our study, we could analyze the duration of motor weakness in hours. To the best of our knowledge this has not been done before. We could show that significant differences exist between mean duration of symptoms of the postoperative ASIA grade groups, improvement and quality of walking groups with a better outcome for shorter time intervals. This is consistent with the preceding studies and reinforces the aforementioned dogma.

The most probable reasons for the association that early surgical decompression results in better neurological outcome is that malignant spinal cord compression leads to edema, venous congestion and secondary vascular injury with decreased arterial blood supply and finally infarction [6,35]. Early surgical decompression before irreversible spinal cord damage occurs does at least theoretically result in a higher recovery rate and a better neurological outcome $[6,36]$.

\section{Ambulation}

The preoperative ability to walk (ambulate) even with a cane ore a walker is a significant predictor for postoperative neurological outcome and postoperative ambulatory status [13-16,18,20,37,38] one study demonstrated that ambulatory status is the single most important predictor [17]. The present study showed that the ability to walk preoperatively is an important predictor for the neurological outcome after decompressive surgery in MESCC however not the single most important one.

Additonally maintaining or regaining the ability to walk contributes to a better life quality and may indirectly [35].

Chaichana et al. [32] found higher percentages of patients regaining ambulatory function after decompressive surgery in lung cancer patients and higher survival rates in patients with breast and kidney cancer and melanoma than in other tumor groups.

Unlike this study we could not find any significant differences between primary tumor groups for the outcome variables.

\section{Age}

Age is a significant predictor for the outcome in various neurological diseases. Therefor it seems reasonable to suppose that this is true in patients with MESCC. A large retrospective study however could not find any significant differences in mean age between ambulatory and non-ambulatory patients [14]. However a randomized clinical trial showed that age is an important variable in predicting preservation of ambulation and survival for patients being treated for MESCC [39]. This is consistent with the findings of our study which showed significant differences in mean age between the ambulatory and nonambulatory patients and the quality of walking groups. These findings may help in selecting patients for surgical or non- surgical intervention based on outcome [39].

\section{Decision making in MESCC}

MESCC is a serious complication in cancer patients leading to pain and neurological compromise. The goal of treatment are pain relief, preservation or recovery of neurological function especially ambulation and restoration or preservation of spinal stability $[40,41]$ Oncologists 
treating this complication in cancer patients need to consider many factors: general status of the patient, comorbidities, age, histological type of the primary tumor and life expectancy $[23,41]$.

\section{Limitations of the study}

This study included a series of consecutive cancer patients with MESCC and neurological compromise. However, it is limited by its retrospective nature and is therefore not suitable to make causal conclusions. However, its value is that it demonstrates the impact of duration of motor weakness on a quite large patient collective.

\section{Conclusion}

The data of this study show that the most important predictors of the early neurological outcome after decompression in patients with symptomatic MESCC are the preoperative neurological status with the ability to walk, the time between onset of symptoms and surgery and age. Less important is the location of the tumor with respect to the spinal cord. Neurological impairment is only one factor which needs to be considered in patients with MESCC. However. if the decision is made to proceed with surgery, decompression of the spinal cord needs to be done early before the patient loses ambulation.

\section{Conflict of interest}

The authors declare no conflict of interest

\section{Human rights statements and informed consent}

All procedures were in accordance with the institutional and national standards and with the Helsinki Declaration of 1975, revised in 2008. The study was approved by the Institutional Review Board of the Goethe University Frankfurt.

\section{Financial support}

The authors have not received any funding for this study.

\section{References}

1. Byrne TN (1992) Spinal cord compression from epidural metastases. $N$ Engl J Med 327: 614-619. [Crossref]

2. Loblaw DA, Perry J, Chambers A, Laperriere NJ (2005) Systematic review of the diagnosis and management of malignant extradural spinal cord compression: The Cancer Care Ontario Practice Guidelines Initiative's Neuro-Oncology Disease Site Group. J Clin Oncol 23: 2028-2037. [Crossref]

3. Bach F, Larsen BH, Rohde K, Børgesen SE, Gjerris F, et al. (1990) Metastatic spinal cord compression. Occurrence, symptoms, clinical presentations and prognosis in 398 patients with spinal cord compression. Acta Neurochir (Wien) 107: 37-43. [Crossref]

4. Helweg-Larsen S, Sørensen PS (1994) Symptoms and signs in metastatic spinal cord compression: a study of progression from first symptom until diagnosis in 153 patients. Eur J Cancer 30A: 396-398. [Crossref]

5. Bilsky MH, Lis E, Raizer J, Lee H, Boland P (1999) The diagnosis and treatment of metastatic spinal tumor. Oncologist4: 459-469. [Crossref]

6. Patchell R a, Tibbs P a, Regine WF, Payne R, Saris S, et al. (2005) Direct decompressive surgical resection in the treatment of spinal cord compression caused by metastatic cancer: a randomised trial. Lancet. 366: 643-648. [Crossref]

7. Husband DJ (1998) Malignant spinal cord compression: prospective study of delays in referral and treatment. BMJ317: 18-21. [Crossref]

8. Hatrick NC, Lucas JD, Timothy AR, Smith MA (2000) The surgical treatment of metastatic disease of the spine. Radiother Oncol 56: 335-339. [Crossref]

9. Bakar D, Tanenbaum JE, Phan K (2016) Decompression surgery for spinal metastases: a systematic review. Neurosurg Focus 41: E2.[Crossref]

10. Boogerd W, van der Sande JJ (1993) Diagnosis and treatment of spinal cord compression in malignant disease. Cancer Treat Rev 19: 129-150.[Crossref]
11. Harris JK, Sutcliffe JC, Robinson NE (1996) The role of emergency surgery in malignant spinal extradural compression: assessment of functional outcome. $\mathrm{Br} J$ Neurosurg 10:27-33. [Crossref]

12. Quraishi NA, Rajagopal TS, Manoharan SR, Elsayed S, Edwards KL, et al. (2013) Effect of timing of surgery on neurological outcome and survival in metastatic spinal cord compression. Eur Spine J22: 1383-1388. [Crossref]

13. Ghogawala Z, Mansfield FL, Borges LF (2001) Spinal radiation before surgical decompression adversely affects outcomes of surgery for symptomatic metastatic spinal cord compression. Spine (Phila Pa 1976) 26:818-824. [Crossref]

14. Chaichana KKL, Woodworth GGF, Sciubba DM, McGirt MJ, Witham TJ, et al. (2008) Predictors of ambulatory function after decompressive surgery for metastatic epidural spinal cord compression. Neurosurgery. 62:683-692. [Crossref]

15. Kondo T, Hozumi T, Goto T, Seichi A, Nakamura K (2008) Intraoperative radiotherapy combined with posterior decompression and stabilization for non-ambulant paralytic patients due to spinal metastasis. Spine (Phila Pa 1976)33:1898-1904. [Crossref]

16. Park JH, Rhim SC, Jeon SR (2011) Efficacy of decompression and fixation for metastatic spinal cord compression: Analysis of factors prognostic for survival and postoperative ambulation. J Korean Neurosurg Soc 50: 434-440. [Crossref]

17. Majeed H, Kumar S, Bommireddy R, Klezl Z, Calthorpe D (2012) Accuracy of prognostic scores in decision making and predicting outcomes in metastatic spine disease. Ann R Coll Surg Engl94: 28-33. [Crossref]

18. Putz C, Gantz S, Bruckner T, Moradi B, Helbig L, et al. (2014) Preoperative scoring and limits of prognostication: Functional outcome after surgical decompression in metastatic spinal cord compression. Oncology 86:177-184. [Crossref]

19. Lei M, Liu Y, Yan L, Tang C, Liu S, et al. (2015) Posterior decompression and spine stabilization for metastatic spinal cord compression in the cervical spine. A matched pair analysis. Eur J Surg Oncol41:1691-1688. [Crossref]

20. Park SJ, Lee CS, Chung SS (2016) Surgical results of metastatic spinal cord compression (MSCC) from non-small cell lung cancer (NSCLC): analysis of functional outcome, survival time, and complication. Spine J 16:322-328.[Crossref]

21. Maynard FM, Bracken MB, Creasey G, Ditunno JF, Donovan WH, et al. (1997) International Standards for Neurological and Functional Classification of Spinal Cord Injury. American Spinal Injury Association. Spinal Cord35: 266-274. [Crossref]

22. Jain NB, Sullivan M, Kazis LE, Tun CG, Garshick E (2007) Factors associated with health-related quality of life in chronic spinal cord injury. Am J Phys Med Rehabil 86 387-396.[Crossref]

23. Fehlings MG, Nater A, Tetreault L, Kopjar B, Arnold P, et al. (2016) Survival and clinical outcomes in surgically treated patients with metastatic epidural spinal cord compression: Results of the prospective multicenter AOSpine study. J Clin Oncol34: 268-276. [Crossref]

24. Nater A, Fehlings MG (2016) Survival and clinical outcomes in patients with metastatic epidural spinal cord compression after spinal surgery: A prospective, multicenter, observational cohort study. Chin J Cancer35: 4-6. [Crossref]

25. Nater A, Martin AR, Sahgal A, Choi D, Fehlings MG (2017) Symptomatic spina metastasis: A systematic literature review of the preoperative prognostic factors for survival, neurological, functional and quality of life in surgically treated patients and methodological recommendations for prognostic studies. PLoS One 12: 1-27. [Crossref]

26. Valesin Filho ES, de Abreu LC, Lima GH, de Cubero DI, Ueno FH, et al. (2013) Pain and quality of life in patients undergoing radiotherapy for spinal metastatic disease treatment. Int Arch Med6:6.[Crossref]

27. Fehlings MG, David KS, Vialle L, Vialle E, Setzer M, et al. (2009) Decision making in the surgical treatment of cervical spine metastases. Spine (Phila Pa 1976) 34: S108117. [Crossref]

28. Fourney DR, Frangou EM, Ryken TC, Dipaola CP, Shaffrey CI, et al. (2011) Spina instability neoplastic score: an analysis of reliability and validity from the spine oncology study group. J Clin Oncol29:3072-3077. [Crossref]

29. Fisher CG, Schouten R, Versteeg AL, Boriani S, Varga P, et al. (2014) Reliability of the Spinal Instability Neoplastic Score (SINS) among radiation oncologists: an assessment of instability secondary to spinal metastases. Radiat Oncol9:69. [Crossref]

30. Fisher CG, Versteeg AL, Schouten R, Boriani S, Varga PP, et al. (2014) Reliability of the spinal instability neoplastic scale among radiologists: An assessment of instability secondary to spinal metastases. AJR Am J Roentgenol203: 869-874.[Crossref]

31. Arana E, Kovacs FM, Royuela A, Asenjo B, Pérez-Ramírez Ú, et al. (2016) Spine Instability Neoplastic Score: agreement across different medical and surgical specialties. Spine J 16: 591-599. [Crossref] 
32. Chaichana KL, Pendleton C, Sciubba DM, Wolinsky J-P, Gokaslan ZL (2009) Outcome following decompressive surgery for different histological types of metastatic tumors causing epidural spinal cord compression. Clinical article. J Neurosurg Spine11: 56-63. [Crossref]

33. Fürstenberg CH, Wiedenhöfer B, Gerner HJ, Putz C (2009) The effect of early surgical treatment on recovery in patients with metastatic compression of the spinal cord. $J$ Bone Joint Surg Br 91: 240-244.[Crossref]

34. Levack P, Graham J, Collie D, Grant R, Kidd J, et al. (2002) Don't wait for a sensory level--listen to the symptoms: a prospective audit of the delays in diagnosis of malignant cord compression. Clin Oncol (R Coll Radiol)14: 472-480. [Crossref]

35. Cole JS, Patchell RA (2008) Metastatic epidural spinal cord compression. Lance Neurol 7: 459-466.[Crossref]

36. Klimo P, Thompson CJ, Kestle JRW, Schmidt MH (2005) A meta-analysis of surgery versus conventional radiotherapy for the treatment of metastatic spinal epidural disease. Neuro Oncol7:64-76.[Crossref]
37. Park JH, Jeon SR (2013) Pre- and postoperative lower extremity motor power and ambulatory status of patients with spinal cord compression due to a metastatic spinal tumor. Spine (Phila Pa 1976)38:E798-802. [Crossref]

38. Lei M, Liu Y, Tang C, Yang S, Liu S, et al. (2015) Prediction of survival prognosis after surgery in patients with symptomatic metastatic spinal cord compression from nonsmall cell lung cancer. BMC Cancer 15:853. [Crossref]

39. Chi JH, Gokaslan Z, McCormick P, Tibbs PA, Kryscio RJ, et al. (2009) Selecting Treatment for Patients with Malignant Epidural Spinal Cord Compression-Does Age Matter? Spine (Phila Pa 1976)34: 431-435. [Crossref]

40. Kilbride L, Cox M, Kennedy CM, Lee SH, Grant R (2010) Metastatic spinal cord compression: a review of practice and care. J Clin Nurs 19: 1767-1783.[Crossref]

41. Lee CH, Kwon JW, Lee J, Hyun SJ, Kim KJ, et al. (2014) Direct Decompressive Surgery Followed by Radiotherapy Versus Radiotherapy Alone for Metastatic Epidural Spinal Cord Compression. Spine (Phila Pa 1976). 39:E587-592. [Crossref]

Copyright: $\odot 2017$ Setzer M. This is an open-access article distributed under the terms of the Creative Commons Attribution License, which permits unrestricted use, distribution, and reproduction in any medium, provided the original author and source are credited. 